\title{
DHL-TauZnNa, a newly synthesized $\alpha$-lipoic acid derivative, induces autophagy in human colorectal cancer cells
}

\author{
TAKAHIRO HIRATSUKA ${ }^{1}$, MASAFUMI INOMATA ${ }^{1}$, YOHEI KONO ${ }^{1}$, \\ SHIGEO YOKOYAMA ${ }^{2}$, NORIO SHIRAISHI ${ }^{1}$ and SEIGO KITANO ${ }^{3}$ \\ Departments of ${ }^{1}$ Gastroenterological Surgery, ${ }^{2}$ Diagnostic Pathology, Oita University Faculty of \\ Medicine, Hasama-machi, Yufu, Oita 879-5593; ${ }^{3}$ Oita University, Oita, Oita 870-1124, Japan
}

Received November 27, 2012; Accepted February 19, 2013

DOI: $10.3892 /$ or.2013.2394

\begin{abstract}
In recent years, several antioxidant substances have been found to have an antiproliferative effect on various types of carcinomas. $\alpha$-lipoic acid (ALA) induces apoptosis in several types of cancer cell lines, but it is difficult to apply $\alpha$-lipoic acid in clinical use as it is easily oxidized and unstable. Recently, we succeeded in synthesizing the $\alpha$-lipoic acid derivative sodium $\mathrm{N}$-[6,8-dimercaptooctanoyl]-2aminoethanesulfonate zinc complex (DHL-TauZnNa), which has highly stable antioxidant effects. We investigated whether DHL-TauZnNa elicits its antiproliferative effects in vivo and in vitro by inducing apoptosis, autophagy or cell cycle arrest, and we analyzed the expression of proteins related to these phenomena and their phosphorylation in HT-29 human colon cancer cells. Subcutaneously administered DHL-TauZnNa treatment applied daily for 41 days significantly inhibited tumor growth by $43 \%$ in a xenograft mouse model $(\mathrm{P}=0.0271)$. DHL-TauZnNa significantly reduced cell viability over that of controls in the trypan-blue exclusion test in a time- and dose-dependent manner $(\mathrm{P}<0.05)$. DHL-TauZnNa increased the proportion of cells in $\mathrm{S}$ phase and decreased that of cells in G0/G1 phase in the cell cycle analysis of HT-29 cells. Although DHL-TauZnNa did not increase caspase-3/7 activity and DNA fragmentation in flow cytometry analysis, it increased the expression of microtubule-associated protein light chain 3-II. Autophagosomes and autolysosomes were observed by electron microscopy in the cytoplasm of HT-29 cells treated with DHL-TauZnNa. These results suggest that DHL-TauZnNa inhibited the proliferation of HT-29 cells through the mechanisms of G2/M cell cycle arrest and autophagy but not that of apoptosis. The newly synthesized ALA derivative DHL-TauZnNa may be expected to become
\end{abstract}

Correspondence to: Dr Takahiro Hiratsuka, Department of Gastroenterological Surgery, Oita University Faculty of Medicine, 1-1 Idaigaoka, Hasama-machi, Yufu-city, Oita 879-5593, Japan E-mail: htakahiru@oita-u.ac.jp

Key words: DHL-TauZnNa, antioxidant, $\alpha$-lipoic acid derivative, G2/M arrest, autophagy a novel cancer therapeutic strategy through its induction of autophagy.

\section{Introduction}

Colorectal cancer is the third most frequently diagnosed cancer worldwide, accounting for more than 1,000,000 cases and 600,000 deaths every year (1). 5-fluorouracil (5-FU), oxaliplatin and irinotecan are considered the global standard of chemotherapy for the treatment of colorectal cancer and have contributed to the improvement in overall survival of colorectal cancer patients (2). These medicines have several biological activities: they inhibit DNA synthesis, DNA replication, or growth signals (3).

In recent years, serum reactive oxygen species levels have been reported to be elevated in proportion to tumor invasion and have shown a significant positive correlation with tumor size in colorectal cancer patients (4). Clinical trials to apply antioxidants to cancer therapy have already been carried out $(5,6), \alpha$-lipoic acid (ALA), vitamin $\mathrm{C}$ and curcumin are known as antioxidants with an antiproliferative effect on cancer cells (5-7). As the mechanisms of their antiproliferative effect, induction of apoptosis and activation of mitogenactivated protein kinases (MAPKs) are reported, but there is as yet no consensus as to the true mechanism.

ALA is one of the most popular antioxidants and is the coenzyme of the intramitochondrial enzyme complex in vivo. ALA induces apoptosis in several cancer cell lines but not in normal human colonocytes $(5,8,9)$, and it is difficult to apply ALA in clinical use as it is easily oxidized and unstable. Recently, we succeeded in synthesizing the ALA derivative sodium N-[6,8-dimercaptooctanoyl]-2-aminoethanesulfonate zinc complex (DHL-TauZnNa), which has highly stable antioxidant effects (Fig. 1).

The aim of the present study was to clarify whether DHL-TauZnNa has an antiproliferative effect on colorectal cancer cells and if so, to elucidate the mechanism of this effect.

\section{Materials and methods}

Reagents. The ALA derivative DHL-TauZnNa was provided by Oga Research, Inc. (Osaka, Japan) (Fig. 1). ALA was 


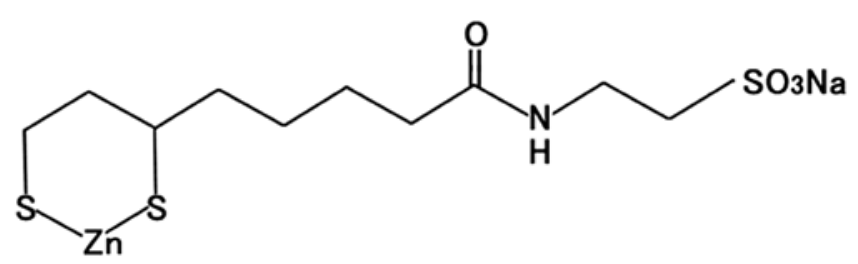

Figure 1. Chemical formula and structure of DHL-TauZnNa. The molecular weight of DHL-TauZnNa is $400.83 \mathrm{Da}$.

purchased from Wako Pure Chemical Industries, Ltd. (Osaka, Japan).

Cell culture. The HT-29 human colorectal cancer cell line was purchased from the American Type Culture Collection (ATCC, Manassas, VA, USA). HT-29 cells were cultured in RPMI1640 medium (Wako Pure Chemical Industries, Ltd.) to which were added $10 \%$ heat-inactivated fetal bovine serum (FBS) and $1 \%$ antibiotic-antimycotic solution containing $100 \mathrm{IU} /$ $\mathrm{ml}$ penicillin, $0.1 \mathrm{mg} / \mathrm{ml}$ streptomycin, and $2.5 \times 10^{-4} \mathrm{mg} / \mathrm{ml}$ amphotericin B (Gibco-BRL Life Technologies, Rockville, $\mathrm{MD}, \mathrm{USA}$ ) in a humidified atmosphere of $5 \% \mathrm{CO}_{2}$ at $37^{\circ} \mathrm{C}$.

Animals. Male BALB/c nu/nu mice weighing 18-21 g (Kyudo Co., Ltd., Saga, Japan) were used in all animal experiments. The mice were maintained at $21^{\circ} \mathrm{C}$ on a 12-h light-dark cycle and given free access to water and standard laboratory chow. This study was approved by the Animal Studies Committee of Oita University, Japan, and was performed according to the National Institutes of Health Standards of Animal Care.

Animal experimental protocol. All mice $(n=30)$ were allowed to acclimate to the unit for 1 week before any manipulations were carried out. Each experimental group consisted of 10 mice. HT-29 tumor cells $\left(3 \times 10^{6}\right)$ suspended in $0.2 \mathrm{ml}$ of sterilized PBS buffer were injected subcutaneously (s.c.) into the back region of each mouse. The mice were then divided into 3 treatment groups 24 h later: the control group, which received $1 \mathrm{~mol} / 1 \mathrm{NaCl}$ s.c. once a day for 42 days; the $0.1 \mathrm{mg}$ DHL-TauZnNa group, which received $0.1 \mathrm{mg} / \mathrm{kg}$ body weight DHL-TauZnNa s.c. once a day for 42 days; and the $1 \mathrm{mg}$ DHL-TauZnNa group, which received $1.0 \mathrm{mg} / \mathrm{kg}$ body weight DHL-TauZnNa s.c. once a day for 42 days. This day was defined as day 1 of the experiment. Tumor size was measured every 2 to 3 days by means of a vernier caliper, and tumor volume was estimated according to the following formula: Tumor volume $=\pi / 6 \times \mathrm{L} \mathrm{x} \mathrm{W}^{2}$, where $\mathrm{L}$ is the greatest dimension of the tumor and $\mathrm{W}$ is the dimension of the tumor in the perpendicular direction (10). Animals were sacrificed under anesthesia 42 days after treatments, and blood and tissue samples were harvested for analysis. The tumor tissue samples were stored at $-80^{\circ} \mathrm{C}$ until examination.

Cell viability. Trypan blue exclusion test was performed to examine the effects of DHL-TauZnNa, ALA and $\mathrm{ZnCl}_{2}$ on cell viability of HT-29 cells. DHL-TauZnNa and ALA were diluted in cell culture medium and regulated to final concentrations of $0.25,0.5$ and $1 \mathrm{mM}$. Cells $\left(1 \times 10^{6}\right)$ cultured in a $25-\mathrm{cm}^{2}$ flask were treated with either ALA or DHL-TauZnNa at different concentrations $(0.25,0.5$ or $1 \mathrm{mM})$ for 24,48 and $72 \mathrm{~h}$ at $37^{\circ} \mathrm{C}$ in a $5 \% \mathrm{CO}_{2}$ incubator. We collected the trypsinized cells that adhered to the flask. The cells were washed and resuspended in PBS. We added $10 \mu \mathrm{l}$ of $0.4 \%$ trypan blue stain (Invitrogen, Eugene, OR, USA) to the $10-\mu 1$ suspension. We placed this mixed liquor on Countess chamber slides (Life Technologies Japan Ltd., Tokyo, Japan) and counted the viable cells with an automated cell counter (Life Technologies Japan) (11).

Analysis of the cell cycle distribution. Cells $\left(1 \times 10^{6}\right)$ were incubated with $0.5 \mathrm{mM}$ DHL-TauZnNa for $48 \mathrm{~h}$, harvested by trypsinization, and fixed with $1 \%$ paraformaldehyde followed by $70 \%$ ice-cold ethanol. The fixed cells were washed in PBS and added to propidium iodide (PI)/RNase staining buffer (BD Pharmingen, Oxford, UK). The cell cycle distribution was analyzed by a FACSCalibur flow cytometer (BectonDickinson, San Jose, CA, USA) according to the manufacturer's instructions (12). Results are displayed as histograms and are expressed as the percentage of cells in each phase of the cell cycle.

Analysis of apoptosis by caspase-3/7 activity. Caspase-3/7 activities of the HT-29 cells and tumors that were treated with ALA or DHL-TauZnNa were detected using a Caspase-Glo ${ }^{\circledR}$ 3/7 Assay kit (Promega Corp. Madison, WI, USA) according to the manufacturer's protocol. Cells $\left(1 \times 10^{4}\right)$ were incubated in a $1.5-\mathrm{ml}$ tube for $24 \mathrm{~h}$ at $37^{\circ} \mathrm{C}$ in $5 \% \mathrm{CO}_{2}$ and treated with $0.5 \mathrm{mM}$ DHL-TauZnNa and 0.5 mM ALA for 3, 12 and $24 \mathrm{~h}$. Cells and tumor extracts were added to $100 \mu \mathrm{l}$ caspase-3/7 reagent and incubated at room temperature in a dark place for $30 \mathrm{~min}$. Fluorescence of the samples was measured with a GloMax $^{\circledR}$ 20/20 Luminometer (Promega Corp.).

Analysis of apoptosis by flow cytometry. Cells $\left(1 \times 10^{6}\right)$ treated with $0.5 \mathrm{mM}$ DHL-TauZnNa were incubated for 6,24 and $48 \mathrm{~h}$, harvested by trypsinization, and fixed with $1 \%$ paraformaldehyde followed by $70 \%$ ice-cold ethanol. Apoptosis was analyzed using the APO-BrdU ${ }^{\mathrm{TM}}$ kit (Becton-Dickinson) according to the manufacturer's instructions (13). Cells were analyzed using a FACSCalibur flow cytometer (BectonDickinson) using at least 10,000 cells/sample. The results are displayed as histograms.

Western blot analysis. Cells were treated in $0.5 \mathrm{mM}$ DHL-TauZnNa for 6 or $24 \mathrm{~h}$, homogenized with Mammalian Protein Extraction Reagents (M-PER ${ }^{\circledR}$; Pierce Biotechnology, Rockford, IL, USA), and sonicated 3 times on ice for $10 \mathrm{sec}$ each with a 1-min interval between each sonication using a Tomy UD-200 sonicator (Tomy, Tokyo, Japan). Lysates were added to 2-mercaptoethanol and boiled for $5 \mathrm{~min}$ at $100^{\circ} \mathrm{C}$. Proteins ( $75 \mu \mathrm{g} / \mathrm{sample}$ ) were separated by sodium dodecyl sulfate-polyacrylamide gel electrophoresis and transferred onto nitrocellulose membranes. Membranes were blocked with $1 \%$ non-fat dry milk in Tris-buffered saline (TBS) with $0.1 \%$ Tween 20 and incubated with primary antibodies against microtubule-associated protein light chain 3 (LC-3) and $\beta$-actin (both from Abcam PLC, Cambridge, UK) for $24 \mathrm{~h}$ at $4^{\circ} \mathrm{C}$ in a refrigerator. The membranes were washed with $0.1 \%$ 
A

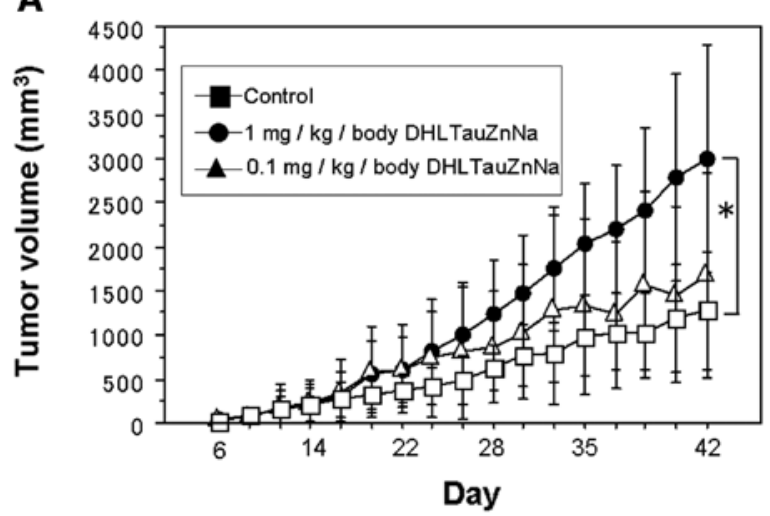

B

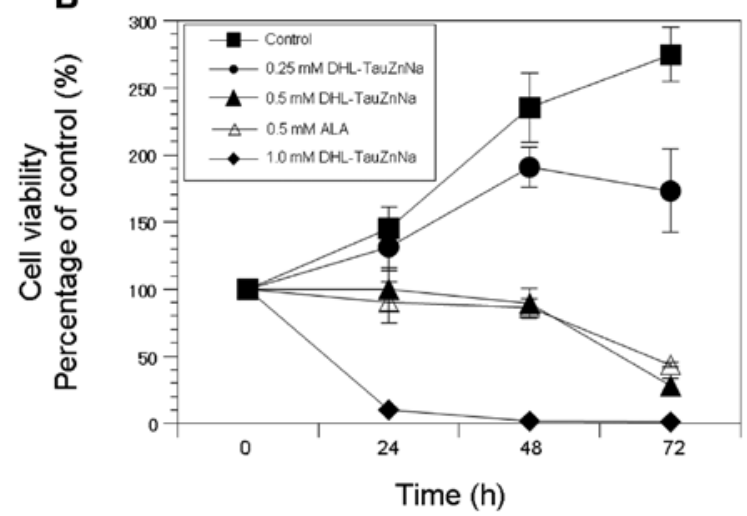

Figure 2. Effects of DHL-TauZnNa on tumor growth in vivo. (A) DHL-TauZnNa treatment decreased xenograft tumor growth in nude mice. Animals received either DHL-TauZnNa (0.1 mg or $1.0 \mathrm{mg} / \mathrm{kg}$ body weight, s.c.) or saline ( $1.0 \mathrm{~mol} / 1$, s.c.) once a day for 42 days. Data are expressed as means $\pm \mathrm{SD}\left({ }^{*} \mathrm{P}<0.05, \mathrm{n}=10\right.$, respectively). (B) Cell viability of HT-29 cells following treatment with DHL-TauZnNa or $\alpha$-lipoic acid (ALA) is shown as a percentage of the control. Values are expressed as the mean of five independent experiments. Error bars indicate standard deviations (SD).

Tween 20 in TBS and then incubated with anti-mouse and antirabbit secondary antibodies (Immuno-Biological Laboratories Co., Ltd., Fujioka, Japan) at room temperature for $60 \mathrm{~min}$. Proteins were visualized with ECL Western blot analysis detection reagent (GE Healthcare UK Ltd., Buckinghamshire, $\mathrm{UK})$. Images were analyzed with ImageJ software (NIH Image, Bethesda, MD, USA).

Electron microscopy. Cells were treated with $0.5 \mathrm{mM}$ DHL-TauZnNa for 6 or $24 \mathrm{~h}$, and non-treated cells were immersed in $2.5 \%$ glutaraldehyde and $2 \%$ paraformaldehyde in $0.1 \mathrm{M}$ cacodylate buffer, $\mathrm{pH} 7.4$ (Karnovsky's fixative), at $4^{\circ} \mathrm{C}$ for $2 \mathrm{~h}$ and postfixed in cacodylate-buffered $2 \%$ osmium tetroxide and $0.5 \%$ potassium ferrocyanide $\left(\mathrm{pH} \mathrm{7.4)}\right.$ at $4{ }^{\circ} \mathrm{C}$ for $2 \mathrm{~h}$. The cells were then dehydrated in a graded ethanol series and embedded in epoxy resin. Ultrathin sections (80-85 nm) were stained with uranyl acetate and lead citrate and examined with an H-7650 transmission electron microscope (Hitachi, Tokyo, Japan).

Phosphorylated protein analysis. Cells $\left(1 \times 10^{6}\right)$ were treated with $0.5 \mathrm{mM}$ DHL-TauZnNa for 6 or $24 \mathrm{~h}$. Protein lysates were obtained from samples collected at each time point using a cell lysis kit (Bio-Rad Laboratories, Hercules, CA, USA). Phosphorylated extracellular signal-regulated kinase 1/2 (ERK1/2), c-Jun N-terminal kinases (JNK), Akt and p38 MAPK were detected using the Bio-Plex ${ }^{\circledR}$ phosphoprotein assay (Bio-Rad Laboratories) and the Phosphoprotein Testing reagent kit (Bio-Rad Laboratories) according to the manufacturer's instructions (14). The proteins were analyzed with the Bio-Plex ${ }^{\circledR}$ Suspension Array system (Luminex 100, Bio-Rad Phosphoprotein Testing reagent kit).

Statistical analysis. We conducted at least three or more independent experiments for all experiments. Data are shown as means \pm standard deviation (SD). Data were analyzed by the Mann-Whitney U test for single comparisons and by analysis of variance (ANOVA) followed by Scheffé's post hoc test for group pairs for multiple comparisons. A value of $\mathrm{P}<0.05$ was considered to be statistically significant. StatView Version 5.0
(Abacus Concepts Inc., Berkeley, CA, USA) was used for all statistical analyses.

\section{Results}

Examination of the tumor growth of the implanted HT-29 colon cancer cells. We initially evaluated the effects of DHL-TauZnNa administration $(0.1$ and $1.0 \mathrm{mg} / \mathrm{kg}$ body weight) on tumor growth in a xenograft model in which HT-29 cells were injected into the subcutis of nude mice. On day 42 of the experiment, the control group had a mean tumor volume of $3001 \mathrm{~mm}^{3}$, whereas the $0.1 \mathrm{mg}$ and $1.0 \mathrm{mg} /$ $\mathrm{kg}$ body weight DHL-TauZnNa groups had mean tumor volumes of 1278 and $1680 \mathrm{~mm}^{3}$, respectively. Subcutaneously administered DHL-TauZnNa $(0.1 \mathrm{mg} / \mathrm{kg}$ body weight $)$ applied daily for 42 days significantly inhibited tumor growth by 43\% ( $\mathrm{P}=0.0271)$ (Fig. 2A). All mice completed the treatment period, and there were no deaths during the treatment.

Examination of the cell viability of HT-29 colon cancer cells. DHL-TauZnNa at concentrations of $0.25,0.5$ and $1 \mathrm{mM}$ significantly reduced cell viability when compared with the cell viability of the controls as detected by the trypan-blue exclusion test at 48 and $72 \mathrm{~h}$, respectively $(\mathrm{P}<0.05)$ (Fig. 2B). Both ALA and DHL-TauZnNa reduced cell viability in a dose- and time-dependent manner. The cytotoxic effect of DHL-TauZnNa was stronger than that of ALA at the concentration of $0.5 \mathrm{mM}$ at $72 \mathrm{~h}(\mathrm{P}<0.05)$. There were no statistically significant differences in the antiproliferative effect or cytotoxic effect at concentrations of 0.25 and $1 \mathrm{mM}$.

Analysis of the cell cycle distribution. Cell cycle analysis by flow cytometry showed an accumulation of HT-29 cells in the G2/M phase after exposure to $0.5 \mathrm{mM}$ of DHL-TauZnNa. The percentages of cells in the G0/G1 and S phases following treatment with DHL-TauZnNa were significantly decreased to a greater extent when compared with these percentages in the control cells $(43.7 \pm 0.90$ vs. $66.9 \pm 3.87 \%, \mathrm{P}<0.0001 ; 17.3 \pm 3.04$ vs. $23.4 \pm 2.15 \%, \mathrm{P}<0.017$, respectively), and the percentage of cells in the $\mathrm{G} 2 / \mathrm{M}$ phase was significantly increased to a greater 


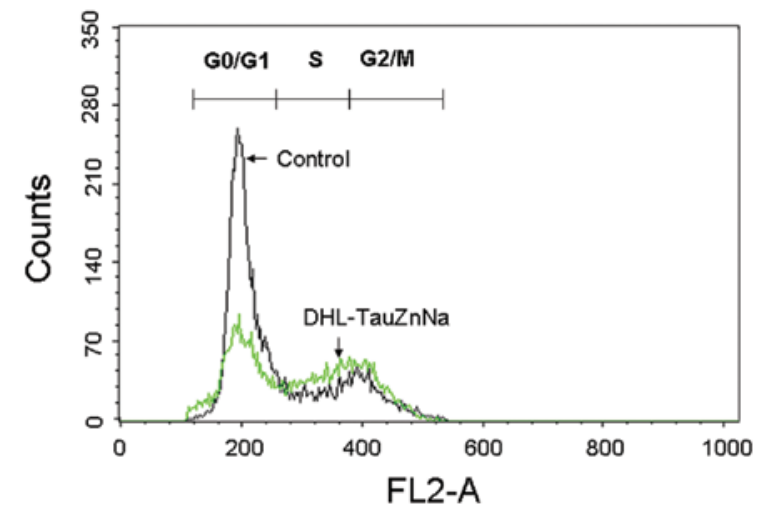

Figure 3. Effects of DHL-TauZnNa on the cell cycle of HT-29 cells. HT-29 cells were treated with $0.5 \mathrm{mM}$ DHL-TauZnNa for $48 \mathrm{~h}$. The cells were stained with propidium iodide to determine the DNA content. Histograms display the cell cycle distribution of the HT-29 cells.

A

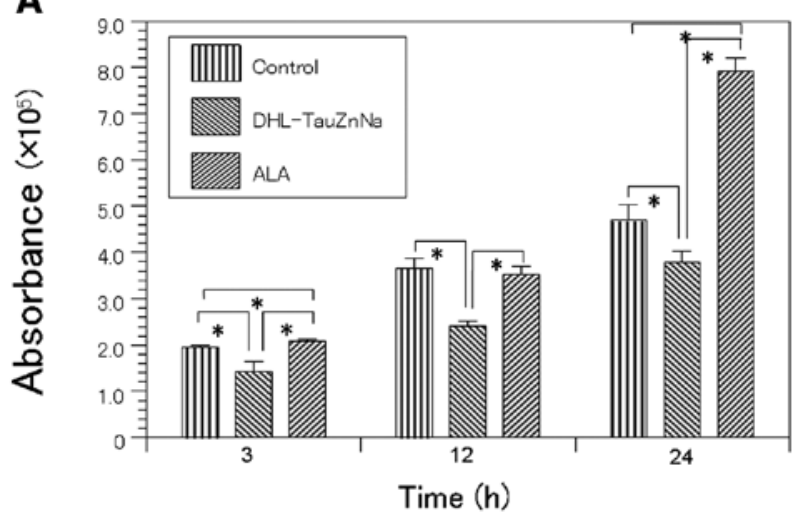

B
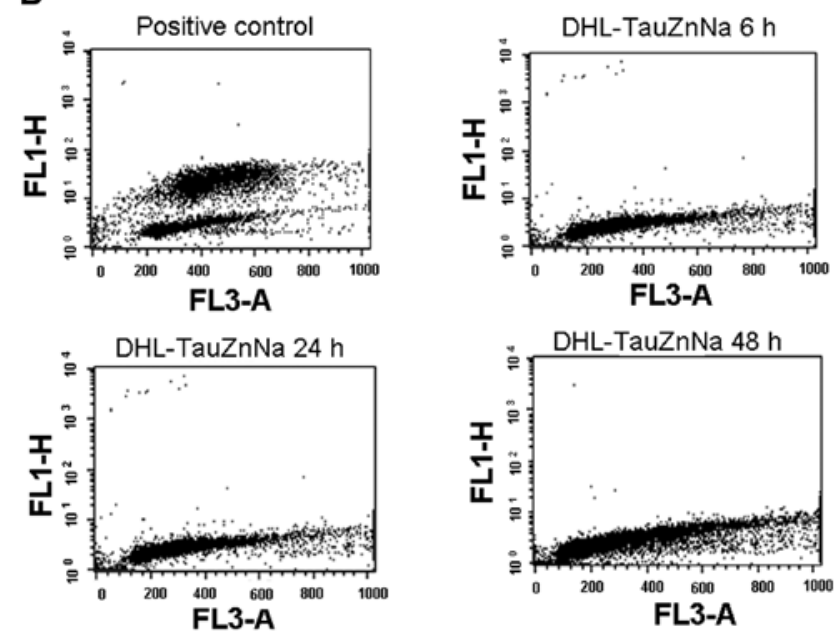

Figure 4. (A) Analysis of caspase-3/7 levels in HT-29 cells following treatments with DHL-TauZnNa and ALA. (B) Detection of apoptotic cells by flow cytometry. Apoptotic cells, which have fragmented DNA and are highly fluorescent, were observed in the positive control cells, whereas apoptotic cells were not noted following treatment with $0.5 \mathrm{mM}$ DHL-TauZnNa for 6,24 or $48 \mathrm{~h}$ as detected by flow cytometric analysis. Data are expressed as the mean of four independent experiments. ( ${ }^{*} \mathrm{P}<0.05$ vs. control); error bars indicate SD.

extent when compared to that of the control cells $(32.8 \pm 1.72$ vs.16.0 $\pm 0.79 \%, \mathrm{P}<0.0001)$ (Fig. 3).

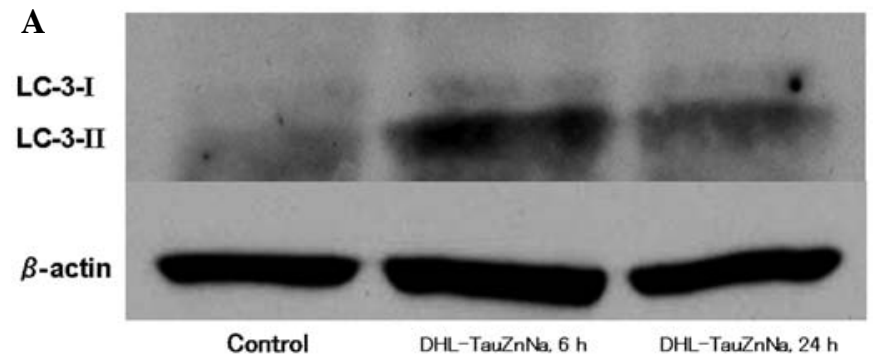

B

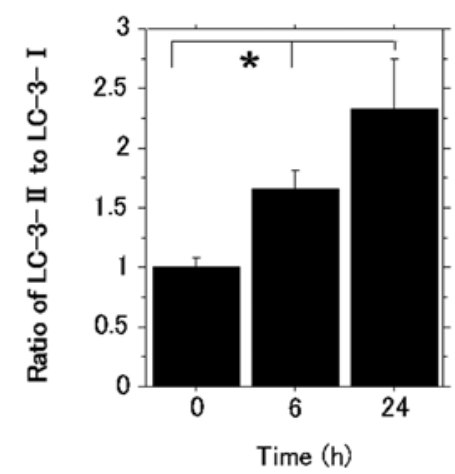

Figure 5. Conversion of LC-3-I to LC-3-II. (A) HT-29 cells were treated with $0.5 \mathrm{mM}$ of DHL-TauZnNa for 6 or $24 \mathrm{~h}$. Non-treated cells were used as a control. The levels of LC-3 were evaluated in the cell extracts by western blot analysis. (B) The ratios of LC-II to LC-I from densitometric analysis were analyzed by one-way ANOVA. Data are shown as means \pm SD values from four independent experiments. ( $\left.{ }^{*} \mathrm{P}<0.05\right)$.

Analysis of apoptosis. Caspase-3/7 activity of the HT-29 cells following treatment with $0.5 \mathrm{mM}$ DHL-TauZnNa was significantly lower than that of the control at 3,12 and $24 \mathrm{~h}$ (each, $\mathrm{P}<0.05$ ), whereas caspase-3/7 activity of the HT-29 cells treated with $0.5 \mathrm{mM}$ ALA at 3 and $24 \mathrm{~h}$ was significantly higher than that of the control. In particular, the caspase-3/7 activity level of ALA at $24 \mathrm{~h}$ was $\sim 1.7$ times that of the control $(\mathrm{P}<0.05)$ (Fig. 4A). Analysis of DNA fragmentation by flow cytometry did not reveal evidence of apoptosis after exposure to $0.5 \mathrm{mM}$ of DHL-TauZnNa (Fig. 4B).

Conversion of LC-3-I to LC-3-II. Treatment of DHL-TauZnNa for 6 and $24 \mathrm{~h}$ more significantly increased the expression of LC-3-II than that of LC-3-I, indicating that DHL-TauZnNa converted LC-3-I to LC-3-II in HT-29 cells $(\mathrm{P}<0.05)$. A significant increase in the expression of LC-3-II over that of LC-3-I was not shown in the control cells (non-treatment with DHL-TauZnNa) (Fig. 5).

Electron microscopy. HT-29 cells either treated with $0.5 \mathrm{mM}$ DHL-TauZnNa or untreated were observed using electron microscopy. A large number of HT-29 cells with loss of membrane integrity and cells with autophagosomes or autolysosomes in the cytoplasm were observed after treatment with $0.5 \mathrm{mM}$ DHL-TauZnNa, and they were regarded as autophagic cells and necrotic cells (Fig. 6A and B). Abnormalities in membrane integrity and organelles in the cytoplasm were not observed in the non-treated cells (Fig. 6C).

Analysis of phosphorylated proteins associated with the MAPK cascade and phosphorylated p53 protein. Levels of 

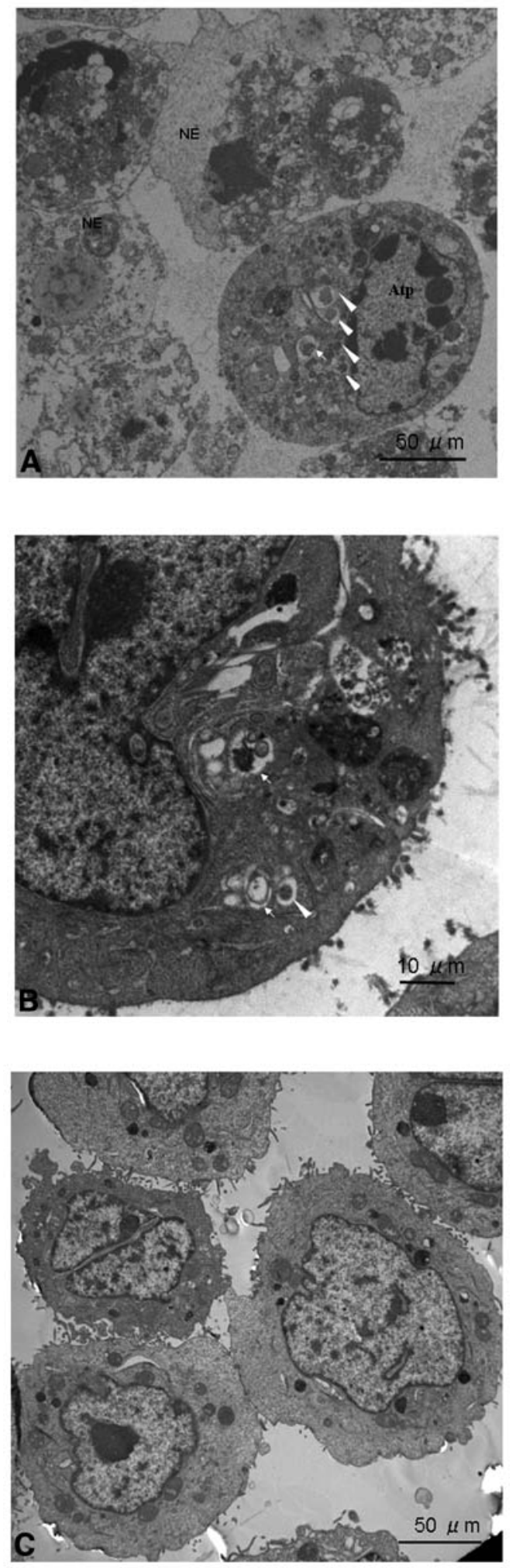

Figure 6. Electron microscopic examination. Electron microscopy evaluation of HT-29 cells after the treatment of (A and B) $0.5 \mathrm{mM}$ DHL-TauZnNa or (C) non-treated cells. White arrows indicate autophagosomes, and white arrowheads indicate autolysosomes. NE, necrotic cell; Atp, autophagic cell.

ERK1/2 and p53 phosphorylated proteins were significantly increased to a greater extent in the HT-29 cells treated with $0.5 \mathrm{mM}$ DHL-TauZnNa when compared with these levels in the control cells at 6 and $24 \mathrm{~h}$ (both, $\mathrm{P}<0.05)$. Furthermore, levels of JNK and p38 MAPK were significantly increased

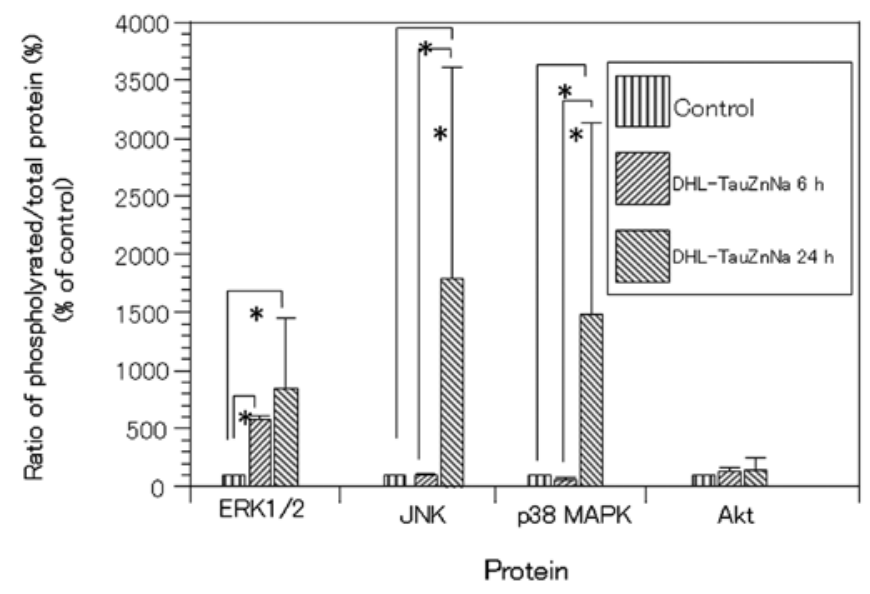

Figure 7. Effects of DHL-TauZnNa on expression of phosphoproteins. HT-29 cells were treated with $0.5 \mathrm{mM}$ DHL-TauZnNa for 6 or $24 \mathrm{~h}$. Proteins purified from samples collected at the indicated time points were analyzed. The ratio of phosphorylated protein to total protein is shown relative to that of the untreated control cells. Data are shown as the means \pm SD values from four independent experiments. ( $\mathrm{P}<0.05)$.

to a greater extent than levels in the control cells at $24 \mathrm{~h}$ (both, $\mathrm{P}<0.05)$. Phosphorylated Akt levels were not changed compared with those in the control at 6 and $24 \mathrm{~h}$ (Fig. 7).

\section{Discussion}

The present study is the first report of the anticancer action of DHL-TauZnNa, a newly synthesized ALA derivative, on HT-29 human colorectal cancer cells both in vitro and in vivo. Our results indicated that DHL-TauZnNa had both cytotoxic and antiproliferative effects on colorectal cancer cells, resulting in cell death and G2/M-phase cell cycle arrest. DHL-TauZnNa did not increase caspase-3/7 activity or DNA fragmentation, suggesting that DHL-TauZnNa did not induce apoptosis, unlike the action of ALA, but resulted in non-apoptotic cell death, autophagy, characterized by the appearance of cells with autophagic vacuoles as detected by electron microscopy, and elevation of LC3-II expression. In the future, DHL-TauZnNa may be a useful anticancer drug.

DHL-TauZnNa was derived by coupling ALA and taurine and then binding zinc to the thiol group. Although ALA is prone to oxidation, polymerization, and desulfurization and is hard to dissolve in water, DHL-TauZnNa is stable, difficult to polymerize and desulfurize and is water soluble. Furthermore, DHL-TauZnNa had potent hydroxyl radical scavenging activity greater than that of ALA in our study (data not shown).

The present study demonstrated that DHL-TauZnNa inhibited the proliferation of HT-29 cells by inducing autophagy but not apoptosis. Autophagic cell death has been considered a primary mechanism for tumor suppression (15). Chang et al (16) reported that cancer cell death was induced through activation of autophagy instead of apoptosis in vitro and showed antiproliferative effects in a xenografted mouse model. The most striking evidence for pro-autophagic chemotherapy to overcome resistance to apoptosis in cancer cells comes from the use of temozolomide, a pro-autophagic cytotoxic drug that has demonstrated therapeutic benefits in glioblastoma 
patients and is in clinical trials for several types of apoptosisresistant cancers (17). In addition, Ullman et al (18) reported that autophagy activates necrosis in apoptosis-deficient mouse embryonic fibroblasts. Gamrekelashvili et al (19) reported that necrosis may inhibit cancer recurrence by acquiring tolerance without inducing tumor immunity such as apoptosis. In our study, DHL-TauZnNa showed an antiproliferative effect associated with autophagy in HT-29 cells, which exhibit resistance to apoptosis and chemoresistance (20), suggesting that DHL-TauZnNa may be a new therapeutic strategy against cancer cells with resistance to apoptosis. In the present study, DHL-TauZnNa induced G2/M-phase cell cycle arrest. These actions are very important in cancer therapy since it is commonly known that $\mathrm{G} 2 / \mathrm{M}$ arrest increases radiation sensitivity, and furthermore, it has been reported that autophagy also enhances radiation sensitivity (21). The combination of radiotherapy and DHL-TauZnNa may result in increased antiproliferative activity.

There are a variety of reports on the association of MAPKs and the induction of autophagy. ERK1/2, JNK and P38 MAPK are reported to be associated with inducing or inhibiting autophagy (22-24). Activation of ERK1/2 and/or JNK induces autophagic cell death $(25,26)$. In HT-29 human colon cancer cells, ERK1/2 induces autophagy (27), and activation of JNK is associated with autophagy-mediated cell death (28). Silibinin, an antioxidant, induces autophagic cell death in human fibrosarcoma HT1080 cells via reactive oxygen species-p38 and c-Jun N-terminal kinase pathways (24). Phosphorylated proteins of the MAPK cascade, JNK, p38MAPK and ERK1/2, were enhanced by DHL-TauZnNa in the present study, and levels of both phosphorylated ERK1/2 and LC-3-II were increased following treatment with DHL-TauZnNa at 6 and $24 \mathrm{~h}$. Therefore, phosphorylation of ERK1/2 may be a trigger in a mechanism of autophagic cell death induced by DHL-TauZnNa, a strong antioxidant.

DHL-TauZnNa did not induce apoptosis but produced autophagy. Majewski et al (29) reported that phosphorylated Akt inhibits caspase activity, resulting in the inhibition of apoptosis, whereas inhibition of the phosphorylation of Akt may increase autophagy (30). In our study, DHL-TauZnNa did not significantly alter the phosphorylation of Akt in HT-29 cells. Inhibition of apoptosis or progression of autophagy in the present study may not have been related to Akt. This study analyzed only the effect on HT-29 cells, and further study is necessary to clarify these issues.

In conclusion, induction of autophagy, but not apoptosis, by DHL-TauZnNa inhibited the proliferation of HT-29 cells in vitro and in vivo. This mechanism was associated with an increase in phosphorylated MAPKs, ERK1/2, JNK and p38. Elucidation of the mechanism of autophagic cell death initiation and knowledge of the pharmacokinetics and side effects of DHL-TauZnNa are necessary before DHL-TauZnNa can be used in the clinical setting in the future. Newly synthesized ALA derivative DHL-TauZnNa may be expected to become a novel cancer therapeutic strategy through its induction of autophagy.

\section{Acknowledgements}

We would like to express our gratitude to Dr Kazumi Ogata, who synthesized and provided the drugs used in this study, and to Ms. Yuiko Asou, Ms. Aiko Yasuda and Ms. Kaori Sakai for their technical assistance. This study was supported in part by Grants-in-Aid for Scientific Research (C) from the Japan Society for the Promotion of Science (JSPS) (no. 23591967).

\section{References}

1. Bretthauer M: Colorectal cancer screening. J Intern Med 270: 87-88, 2011.

2. Hind D, Tappenden P, Tumur I, et al: The use of irinotecan, oxaliplatin and raltitrexed for the treatment of advanced colorectal cancer: systematic review and economic evaluation. Health Technol Assess 12: iii-ix, xi-162, 2008.

3. Wolpin BM and Mayer RJ: Systemic treatment of colorectal cancer. Gastroenterology 134: 1296-1310, 2008.

4. Inokuma T, Haraguchi M, Fujita F, et al: Oxidative stress and tumor progression in colorectal cancer. Hepatogastroenterology 56: 343-347, 2009.

5. Novotny L, Rauko P and Cojocel C: alpha-Lipoic acid: the potential for use in cancer therapy. Neoplasma 55: 81-86, 2008.

6. Gao P, Zhang H, Dinavahi R, et al: HIF-dependent antitumorigenic effect of antioxidants in vivo. Cancer Cell 12: 230-238, 2007.

7. Kunnumakkara AB, Anand P and Aggarwal BB: Curcumin inhibits proliferation, invasion, angiogenesis and metastasis of different cancers through interaction with multiple cell signaling proteins. Cancer Lett 269: 199-225, 2008.

8. Shi DY, Liu HL, Stern JS, et al: Alpha-lipoic acid induces apoptosis in hepatoma cells via the PTEN/Akt pathway. FEBS Lett 582: 1667-1671, 2008.

9. Wenzel U, Nickel A and Daniel H: alpha-Lipoic acid induces apoptosis in human colon cancer cells by increasing mitochondrial respiration with a concomitant $\mathrm{O}_{2}^{-\cdot}$-generation. Apoptosis 10: 359-368, 2005.

10. Du J, Martin SM, Levine M, et al: Mechanisms of ascorbateinduced cytotoxicity in pancreatic cancer. Clin Cancer Res 16: 509-520, 2010.

11. Altman SA, Randers L and Rao G: Comparison of trypan blue dye exclusion and fluorometric assays for mammalian cell viability determinations. Biotechnol Prog 9: 671-674, 1993.

12. Kalejta RF, Shenk T and Beavis AJ: Use of a membrane-localized green fluorescent protein allows simultaneous identification of transfected cells and cell cycle analysis by flow cytometry. Cytometry 29: 286-291, 1997.

13. Makhov P, Kutikov A, Golovine K, et al: Docetaxel-mediated apoptosis in myeloid progenitor TF-1 cells is mitigated by zinc: potential implication for prostate cancer therapy. Prostate 71: 1413-1419, 2011.

14. Li M, Zhang Y, Zhai Q, et al: Thymosin beta-10 is aberrantly expressed in pancreatic cancer and induces JNK activation. Cancer Invest 27: 251-256, 2009.

15. Tsuchihara K, Fujii S and Esumi H: Autophagy and cancer: dynamism of the metabolism of tumor cells and tissues. Cancer Lett 278: 130-138, 2009.

16. Chang KY, Tsai SY, Wu CM, et al: Novel phosphoinositide 3-kinase/mTOR dual inhibitor, NVP-BGT226, displays potent growth-inhibitory activity against human head and neck cancer cells in vitro and in vivo. Clin Cancer Res 17: 7116-7126, 2011.

17. Lefranc F, Facchini V and Kiss R: Proautophagic drugs: a novel means to combat apoptosis-resistant cancers, with a special emphasis on glioblastomas. Oncologist 12: 1395-1403, 2007.

18. Ullman E, Fan Y, Stawowczyk M, et al: Autophagy promotes necrosis in apoptosis-deficient cells in response to ER stress. Cell Death Differ 15: 422-425, 2008.

19. Gamrekelashvili J, Krüger C, von Wasielewski R, et al: Necrotic tumor cell death in vivo impairs tumor-specific immune responses. J Immunol 178: 1573-1580, 2007.

20. Zhang Y, Yuan J, Zhang HY, et al: Natural resistance to apoptosis correlates with resistance to chemotherapy in colorectal cancer cells. Clin Exp Med 12: 97-103, 2012.

21. Kim KW, Mutter RW, Cao C, et al: Autophagy for cancer therapy through inhibition of pro-apoptotic proteins and mammalian target of rapamycin signaling. J Biol Chem 281: 36883-36890, 2006.

22. Shinojima N, Yokoyama T, Kondo U, et al: Roles of the Akt/mTOR/p70S6K and ERK1/2 signaling pathways in curcumin-induced autophagy. Autophagy 3: 635-637, 2007. 
23. Shimizu S, Konishi A, Nishida Y, et al: Involvement of JNK in the regulation of autophagic cell death. Oncogene 29: 2070-2082, 2010.

24. Duan WJ, Li QS, Xia MY, et al: Silibinin activated p53 and induced autophagic death in human fibrosarcoma HT1080 cells via reactive oxygen species-p38 and c-Jun N-terminal kinase pathways. Biol Pharm Bull 34: 47-53, 2011.

25. Böck BC, Tagscherer KE, Fassl A, et al: The PEA-15 protein regulates autophagy via activation of JNK. J Biol Chem 285: 21644-21654, 2010.

26. Chen SY, Chiu LY, Maa MC, et al: zVAD-induced autophagic cell death requires c-Src-dependent ERK and JNK activation and reactive oxygen species generation. Autophagy 7 : 217-228, 2011

27. Ogier-Denis E, Pattingre S, El Benna J, et al: Erk1/2-dependent phosphorylation of Galpha-interacting protein stimulates its GTPase accelerating activity and autophagy in human colon cancer cells. J Biol Chem 275: 39090-39095, 2000.
28. Xie CM, Chan WY, Yu S, et al: Bufalin induces autophagymediated cell death in human colon cancer cells through reactive oxygen species generation and JNK activation. Free Radic Biol Med 51: 1365-1375, 2011.

29. Majewski N, Nogueira V, Robey RB, et al: Akt inhibits apoptosis downstream of BID cleavage via a glucose-dependent mechanism involving mitochondrial hexokinases. Mol Cell Biol 24: 730-740, 2004.

30. Viola G, Bortolozzi R, Hamel E, et al: MG-2477, a new tubulin inhibitor, induces autophagy through inhibition of the Akt/mTOR pathway and delayed apoptosis in A549 cells. Biochem Pharmacol 83: 16-26, 2012. 